\title{
Tables des figures et des tropes. Seconde partie. Les défauts [Augsburg, 1516]
}

Présentation, traduction et notes : Christine Noille

\section{Petrus Mosellanus}

Christine Noille (éd.)

\section{OpenEdition}

1 Journals

\section{Édition électronique}

URL : http://journals.openedition.org/rhetorique/1068

DOI : $10.4000 /$ rhetorique. 1068

ISSN : 2270-6909

\section{Éditeur}

UGA Éditions/Université Grenoble Alpes

\section{Édition imprimée}

ISBN : 978-2-37747-248-2

\section{Référence électronique}

Petrus Mosellanus, «Tables des figures et des tropes. Seconde partie. Les défauts [Augsburg, 1516] », Exercices de rhétorique [En ligne], 15 | 2020, mis en ligne le 11 novembre 2020, consulté le 03 décembre 2020. URL : http://journals.openedition.org/rhetorique/1068 ; DOI : https://doi.org/10.4000/ rhetorique. 1068

\section{Ce document a été généré automatiquement le 3 décembre 2020.}

\section{(c) (†)}

Les contenus de la revue Exercices de rhétorique sont mis à disposition selon les termes de la Licence Creative Commons Attribution - Pas d'Utilisation Commerciale - Partage dans les Mêmes Conditions 4.0 International. 


\section{Tables des figures et des tropes. Seconde partie. Les défauts [Augsburg, 1516]}

Présentation, traduction et notes : Christine Noille

\section{Petrus Mosellanus}

Christine Noille (éd.)

\section{Présentation}

Or, le discours parfait, comme nous l'avons déjà dit ailleurs, repose sur trois éléments : une langue correcte, des énoncés convaincants et une éloquence ornée. Comme le premier élément, c'est la grammaire qui l'enseigne, le second la dialectique : le troisième, je ne vois absolument pas à quoi l'attribuer, si ce n'est à la rhétorique ; [...] son seul travail visera à la clarté, à l'arrangement < des mots > et au raffinement du discours ${ }^{1}$.

1 Ce dont témoigne Agricola à la fin $\mathrm{du} \mathrm{Xv}^{\mathrm{e}}$ siècle, c'est d'une conception ancienne de la rhétorique, qui l'inscrit à la suite de la grammaire et la focalise sur les techniques des tropes et des figures : et si le grand apport des humanistes du siècle suivant aura été de repositionner la rhétorique du côté de l'art d'argumenter et la lecture rhétorique du côté de l'analyse anatomique (syllogistique) de la dispositio ${ }^{2}$, il n'en reste pas moins que la Renaissance connaît une efflorescence de manuels consacrés aux tropes et aux figure - plus de 180 éditions répertoriées sans compter les quelques 278 éditions de la Rhétorique à Herennius et de l'Institution oratoire ${ }^{3}$.

2 C'est dans ce contexte large qu'il faut placer la parution en 1516 d'un opuscule d'enseignement des figures, les Tabulae de schematibus de Petrus Mosellanus, manuel le plus réédité au $\mathrm{XVI}^{\mathrm{e}}$ siècle (86 éditions) si l'on en croit le décompte de Peter Mack ${ }^{4}$. L'année 1516 voit deux éditions différenciées dans la bibliographie de L. D. Green et J. J. Murphy, à Augsbourg (chez l'imprimeur Philipp Ulhart ${ }^{5}$ : exemplaire disponible sur Google Books) et, attestée seulement par Green et Murphy, à Francfort chez Strechenbach ${ }^{6}$. Parmi les multiples rééditions, nous pouvons en distinguer de deux 
sortes : les unes, qui éditent le texte seul ou l'associent à des rhéteurs antiques ${ }^{7}$; les autres, qui reprennent l'édition de $1526^{8}$ due aux soins de Georg Major (1502-1574), lequel ajoute aux Tabulae de Mosellanus deux épitomés de son propre cru, le premier résumant sous forme de tables la rhétorique de Melanchthon à partir de ses Institutiones rhetoricae (1521), l'autre le De duplici Copia d'Érasme (1512).

3 Avant d'ouvrir les Tabulae de schematibus, quelques mots sur leur auteur: Peter Schade (1494-1524) est né à Proteg sur les bords de la Moselle, d'où sa signature humaniste, Petrus Mosellanus Protegensis. Disciple du grand helléniste anglo-saxon Richard Croke (Crocus, c. 1489-1558), il prend sa succession en 1517 à l'université de Leipzig comme professeur de grec. Ce philologue est aussi un théologien catholique ouvert aux idées de la Réforme, ayant noué dans les dernières années de sa vie une relation étroite avec Melanchthon'.

4 Le manuel que rédige Mosellanus est aux confluents de ses références philologiques : ce qui ne signifie pas qu'il est dépourvu d'originalité, comme en témoigne son intitulé. L'ouvrage affiche d'emblée son orientation pédagogique en se présentant comme des Tabulae, terme à peu près inédit pour des matières littéraires (on notera qu'il apparaît juste dans le titre d'une grammaire grecque publiée la même année par son maître Richard Crocus $^{10}$ ). Quant à la désignation du contenu par l'expression « de schematibus et tropis », elle n'est pas si répandue que cela : elle est parfois utilisée, avant 1516, pour désigner une section à l'intérieur d'une grammaire (en particulier dans le De arte grammatica de Diomède ${ }^{11}$ sous l'autorité duquel Mosellanus place son ouvrage). Mais elle apparaît très rarement pour désigner un opuscule entier : nous n'avons trouvé que deux références éditées ${ }^{12}$, le Carmen de figuris d'Antonio Mancinelli (Rome, Eucharius Silber, 1489) et, nous intéressant plus directement parce qu'également cité par Mosellanus, le titre latin donné par les éditeurs à un opuscule d'un rhéteur grec tardif, le De figuris sensus et dictionis d'Alexandre le Sophiste [Alexandre Numenius], publié dans les Rhetores graeci (Venise, Alde, vol. 1, 1508).

D'où il ressort que Mosellanus s'inscrit à la suite des grammairiens, et cependant en rupture : il extrait sa matière hors du champ de la grammaire, sans l'intégrer pour autant à un autre ensemble disciplinaire plus vaste, qui serait celui de la rhétorique, même si son innutrition de la rhétorique latine est patente - pour l'essentiel en effet, sa méthode consiste à confronter les listes de figures qu'il trouve chez Aelius Donat et Diomède au détail des livres VIII et IX de l'Institution oratoire. Il institue de fait la rhétorique des figures en champ autonome.

6 À partir de là, la démarche de Mosellanus suit celle de Diomède dans la division de l'ensemble (une première partie consacrée aux listes de figures, une seconde aux vices $\mathrm{du}$ discours et une troisième à ses vertus, lesquelles incluent l'usage des tropes $\left.{ }^{13}\right)$, sans s'interdire de remanier le détail des listes. Au niveau de chaque item, la procédure est toujours la même, emblématisant à elle seule la démarche humaniste du philologue : Mosellanus nomme, définit, exemplifie. Il nomme d'abord la figure de son nom grec, puis en donne la translittération latine. Il la définit brièvement dans une proposition qui emprunte en partie ou en totalité à Quintilien et/ou aux grammairiens latins. Il l'exemplifie en reprenant les exemples standards de ses référents ou en en choisissant d'autres. Au bout du compte, sa voix se fait entendre de biais, dans l'ajout d'une comparaison - «ceu nubes", " comme un épais brouillard " précise-t-il par exemple pour évoquer le trouble de la signification lié à l'acyron -, d'une référence (les Nuits attiques d'Aulu-Gelle, dont il publiera une annotation critique) ou d'un corpus 
d'illustration - le théâtre de Térence, à côté de l'inévitable Virgile. Mais ce que perçoit également le lecteur d'aujourd'hui à la recension de ces dizaines de figures (et sans doute les étudiants de l'époque, souvent peu experts en $\operatorname{~grec}^{14}$ ), c'est en quelque sorte la voix, ou plutôt la langue de cette rhétorique de la Renaissance : non pas entièrement latinisée ${ }^{15}$, mais trouée de vocables grecs dont l'exotisme le dispute à la complexité - un univers où la cacozelia voisine avec l'acyron et où la periergia peut être assimilée à la macrologia et à la leptologia...

7 Dans le cadre de la présente livraison d'Exercices de rhétorique sur (et contre) les figures, il nous a alors paru intéressant de donner à lire la liste des fautes oratoires que Mosellanus synthétise à partir des héritages antiques et fixe, vu ses multiples rééditions, pour le siècle à venir. Nous ne sommes pas ici, comme chez Caussin, du côté des vices de style, mais du côté des vices du discours, des tournures qui pèchent contre ces trois valeurs quintiliennes que sont la correction, la clarté et l'ornement (l'ornatus). Il s'agit là d'un âge de l'éloquence qui nous est devenu étranger, où il est possible de faire des fautes oratoires comme il arrive qu'on fasse des fautes de grammaire; et où il existe en conséquence des figures défectueuses comme il existe des figures vertueuses. Et que les poètes fournissent des exemples pour les unes comme pour les autres n'est pas sans ajouter à la difficulté, rappelant la porosité qui existe entre les vices et les vertus, ou plus précisément entre ce qui est ici (en poésie) une licence poétique et là (dans la prose) un travers de l'éloquence ${ }^{16}$.

8 Ce sont donc en tout 17 fautes que Mosellanus retient; et comme Quintilien et Diomède, il les classe en trois ensembles, tout en relativisant le classement ${ }^{17}$ : ce n'est pas le système qui l'intéresse, mais le répertoire. Pour l'analyse détaillée des fautes figurales, nous renvoyons à l'annotation que nous avons apportée à notre traduction. Nous nous contenterons ici de nous interroger sur la postérité de ces listes : car elle est grandement paradoxale, abondante jusqu'à la fin $\mathrm{du} \mathrm{xvI}^{\mathrm{e}}$ siècle, quasi éteinte dès le début du XVII ${ }^{e}$ siècle.

9 Pour le $\mathrm{XvI}^{\mathrm{e}}$ siècle tout d'abord, force est de constater qu'il y a à travers toute l'Europe une véritable surenchère dans le nombre de fautes répertoriées (que ce soient dans des manuels dédiés aux tropes et aux figures ou dans des sections d'ouvrages de rhétorique ou de grammaire) - Louis Carbone en dénombrera 39 dans son Divinus Orator ${ }^{18}$ et un opuscule sera même publié qui portera sur les seuls défauts du discours, les subdivisant en cinq livres d'une vingtaine de chapitres chacun ${ }^{19}$. Nous rappellerons toutefois que Mosellanus n'est pas à lui seul à l'origine de cette inflation. Un autre relai doit être mentionné, proprement séminal en ce qu'il invente de nouvelles figures qui seront attestées dans les listes ultérieures : à savoir le commentaire de Veltkirch au De Copia $\left(1634^{20}\right)$.

10 Il s'agit là d'un commentaire publié de façon posthume par les soins d'un disciple, Vitus Winshemius [Veit Winsheim, 1501-1570], avec une préface de Philippe Melanchthon, où les fautes du discours sont abordées dans le commentaire au chapitre VIII du Livre I : Veltkirch recense 27 fautes figurales, soit que, reprenant la liste de Mosellanus, il dédouble certains items, ce qui lui permet d'introduire l'hyperbate, la macrologie, la brachylogie, la meiôsis, l'eschrologie (aiskhrologia), l'arythmon et l'anoiconometon (ou anoikonomèton); soit qu'il en invente d'autres, en l'occurrence trois nouvelles fautes désignées sous des noms grecs forgés : la bomphiologia, l'asiatismus et la poikilogia ${ }^{21}$. Ces trois défauts entrent de fait en résonance avec des éléments qui font difficulté dans l'opuscule de Mosellanus. Ce dernier en effet a un problème avec la constellation des 
fautes liées à l'enflure (fautes de style, peut-être, plus que de discours) : la macrologie (développement trop long), qu'il ne retient pas dans sa liste, vient cependant troubler et redoubler deux autres défauts, la périssologie (répétition inutile) et la périergie (excès de détail ${ }^{22}$ ). Sur le chapitre qu'Érasme consacre alors à l'utilité de la méthode de copia ("Quas ad res conferat haec exercitatio », "À quelles fins contribue cet exercice »), Veltkirch propose un commentaire d'une ampleur considérable comparée aux commentaires minimalistes des autres chapitres - comme s'il profitait d'un chapitre dédié à l'éloge de la copia pour en dénoncer les risques : non seulement il reprend la périssologie et la périergie, mais il leur ajoute la macrologie et, nous y voilà, les figures de l'enflure (bomphiologia), du verbiage (asiatismus ${ }^{23}$ ) et de la bigarrure (discours chamarré par l'abus des figures : poikilogia).

Toutes ces fautes figurales, les dix-sept que Mosellanus a fixées et les dix supplémentaires qu'a introduites Veltkirch, vont donner lieu à d'innombrables reprises partielles ou totales, avec ou sans variantes, et selon deux modalités parfaitement contradictoires : les uns les intègrent de plain-pied dans leurs listes de figures, oubliant la séparation entre vices et vertus (en particulier dans la tradition anglaise, du côté de Sherry et Peacham ${ }^{24}$ ) ; les autres, les Rivius, Vibotius, Valerius, Erythraeus..., respectent la séparation et les cantonnent à la catégorie des défauts discursifs ${ }^{25}$. C'est ce que fera également Louis de Grenade en 1576, dont nous faisons ici mention parce qu'aux siècles suivants, ces fameuses listes ne survivront plus que dans ses rééditions et traductions ${ }^{26}$ et à leur suite, chez un auteur comme Charles Pajot, le dernier au $\mathrm{XvII}^{\mathrm{e}}$ siècle à connaître encore la bomphiologia, la poikilogia et la periergie ${ }^{27}$.

Pourquoi cette tabula rasa? Nous n'avons pas de réponse ni d'hypothèse convaincante. Tout au plus mentionnerons-nous que les défauts du discours sont totalement absents des manuels pédagogiques jésuites inaugurés par Soarez et réactualisés par Pomey et Jouvancy ${ }^{28}$.

\section{Édition}

\section{Principes d'édition}

Nous donnons le texte de l'édition princeps : Petrus Mosellanus [Peter Schade], Tabulae de schematibus Petri Mosellani a plurimis mendis quam diligentissime repurgatae, adjectis insuper his quae in quibusdam editionibus incuria praetermissa sunt. His praeterea praemisimus Xysti Betuleii de figurata dicendi ratione judicium, Augustae Rheticae [Augsbourg], Philippus Vlhardus excudebat [Philipp Ulhart], p. 25-32. Sans date sur la page de titre : mais daté sub fine de « juillet 1516 »(p. 45, juste avant l'index). Nous indiquerons entre crochets droits les pages de cette édition.

Texte latin corrigé sur collation de l'édition de : Cologne, Eucharius [Cervicornus], 1528, n. p. ; et pour le grec, sur l'édition de : Paris, Chrétien Wechel, 1537, n. p. Dans le latin, nous supprimons les accents et les lettres liées ; résolvons les abréviations; en vue de la recherche automatisée par mots, nous dissimilons le $i$ du $j$ et le $u$ du $v$; enfin, nous ne respectons pas toujours la ponctuation de l'édition de 1516, et sont toujours nôtres le soulignement en gras (pour les noms de figures) et les italiques (hormis celles de la toute dernière phrase sur l'énallage). 
Dans nos notes d'édition, nous renvoyons systématiquement à Donat et Diomède, ainsi qu'au troisième grammairien de la même époque qui leur est associé, Charisius, sans oublier Quintilien. Pour les éditions utilisées, voir :

Aelius Donat, Ars major III, 1 dans Grammatici latini, éd. H. Keil, Leipzig, Teubner, t. IV, 1864, p. 392-395 (pour une édition ultérieure, voir L. Holtz, Donat et la tradition de l'enseignement grammatical, Paris, CNRS Éditions, 1981) ; abrégé en : Donat.

Charisius (Flavius Sosipatrus), Artis grammaticae libri V, V, 1-3, éd. H. Keil, Lepzig, Teubner, t. I, 1857, p. 265-27 ; abrégé en : Charisius.

Diomède, Diomedis artis grammaticae libri III, II, §. « De vitiis orationis », dans Grammatici latini, éd. H. Keil, Lepzig, Teubner, t. I, 1857, p. 449-456 ; abrégé en : Diomède.

Quintilien, Institutio oratoria (abrégé en : Quintilien). Nous traduisons systématiquement d'après la trad. de L. Baudet, Collection des textes latins, dir. M. Nisard, Paris, Dubochet, 1842 ; les numéros de pages indiqués sont ceux de cette édition.

\section{Seconde partie. Les défauts ${ }^{29}$ / Vitium. Schematis pars secunda}

Un défaut est dans l'énoncé comme une erreur qui, si elle est pardonnée chez les poètes, est cependant intolérable dans la prose ${ }^{30}$.

Les défauts sont de trois ordres : l'obscurité, le désordre, l'incorrection ${ }^{31}$.

Vitium in oratione quasi error quidam, qui etsi poetis condonatur, in prosa tamen intolerabilis est.

Species sunt: Obscurum, Inordinatum, Barbarum.

\section{Les fautes relatives à l'obscurité / Obscurum, ejusque partes}

Il y a obscurité quand un défaut dans les mots ou la construction rend l'énoncé obscur $^{32}$.

Les fautes relatives à l'obscurité sont : l'acyron, le pléonasme, la périssologie, la tautologie, l'homologie, l'amphibologie, l'ellipse, la périergie ${ }^{33}$.

[26] Obscurum, cum vel verborum vel structurae vitio obscuritas quaedam inducitur.

Cuius partes habentur: Acyron, Pleonasmos, Perissologia, Tautologia, Homoeologia,

Amphibologia, Eclipsis, Periergia.

Acyron, Impropriété. Quand un terme est appliqué à l'énoncé en troublant complètement la signification propre, comme un épais brouillard ${ }^{34}$. Térence : Peut-être espères-tu que ta conduite suffira pour écarter de toi ${ }^{35}$... Espères-tu à la place de Crains-tu. À la manière dont les Grecs eux-mêmes font usage du verbe espérer.

'Akupov Acyron, Improprietas, cum dictio minime propriae significationis orationi ceu nubes inducitur. Terentius: Nam quod tu speras, propulsabo facile. Speras pro times.

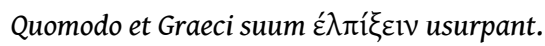

Pléonasme. Se produit chaque fois que, dit Quintilien, l'énoncé est surchargé de mots superflus ${ }^{36}$, comme J'ai vu de mes yeux. Il suffit de dire en effet : J'ai vu. - Énéide, 1 : Voici ce qu'elle dit de sa bouche ${ }^{37}$. 


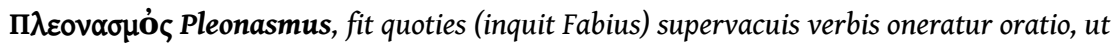
Vidi meis oculis. Satis est enim, vidi. Sic ore lucuta est. Aeneid.1.

Périssologie. Se produit quand une expression est ajoutée sans aucune force dans la pensée ${ }^{38}$, comme le fait Tite-Live au livre 8 de L'Histoire romaine: Les ambassadeurs, n'ayant pu obtenir la paix, s'en retournèrent chez eux, d'où ils étaient venus ${ }^{39}$.

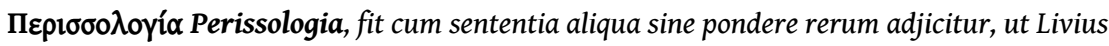
in 8. Ab urbe condita : Legati non impetrata pace, retro domum unde venerant reversi sunt.

Tautologie. Répétition d'un même mot ou d'un même énoncé ${ }^{40}$, défaut où tombe Cicéron lui-même, selon la remarque de Quintilien, lorsqu'il dit, certes < en déclinant le mot > sous un cas différent : Non seulement donc, juges, ce jugement n'a rien qui ressemble à un jugement ${ }^{41}$...

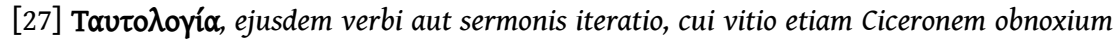
notat Fabius, quod dixit, Non solum igitur illud judicium judicii simile judices non fuit, quamvis casu diverso.

1 Homologie < uniformité > . Défaut plus considérable encore, lorsque l'énoncé, de toute part semblable à lui-même, provoque l'ennui par son absence complète de variété, étant au contraire tout entier d'une seule couleur ${ }^{42}$. Pour ce qui est d'un exemple qui ne soit pas trop long, nous n'en ajoutons pas pour le moment ${ }^{43}$.

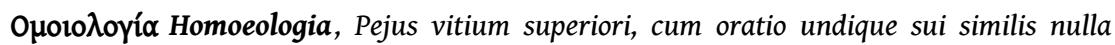
varietatis gratia levat taedium, sed est tota coloris unius. Cujus exemplum, ne nimis longum sit, in praesentiarum non adscribemus.

2 Amphibologie. Quand par un défaut de construction, un mot est susceptible de deux interprétations différentes ${ }^{44}$, à la façon dont l'oracle répond à Pyrrhus : J'affirme, Éacide, $<$ une chose > : < entre > toi < et > les Romains, la victoire est possible ${ }^{45}$. Pour quel parti la victoire est-elle promise ? La chose est incertaine.

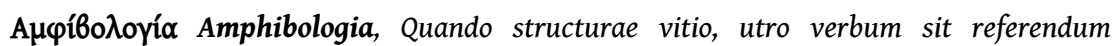
dubitatur, quemadmodum Pyrrho oraculum respondit, Aio te Aeacida, Romanos vincere posse. Hic utri victoria promittatur, incertum.

Ellipse. Suppression, que Quintilien nomme meiôsis (si je ne me trompe) : quand il manque quelque chose à l'énoncé, qui fait qu'il est moins plein ${ }^{46}$, comme dans ... prédestiné, parvint en Italie $e^{47}$, où il manque < en latin la préposition > en. Dans l'Eunuque : Moi, retourner chez elle, qui le... qui me... qui $e^{48} . .$. ?

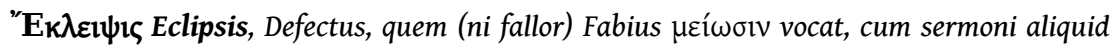
deest, quo minus plenus sit, ut Italiam fato profugus, deest, ad. Egone illam? quae illum? quae me? quae non? In Eunucho.

Périergie < enflure >. Raffinement stylistique superflu et excessif ${ }^{49}$. Ce défaut est le même que celui que Quintilien et Diomède nomment macrologie (ou du moins en est-il très proche), et qu'Alexandre le Sophiste nomme leptologie, c'est-à-dire énoncé minutieux, quand l'énoncé est plus long et plus minutieux qu'il ne convient, en raison d'un < grand > raffinement ${ }^{50}$. Virgile : Le lendemain, le jour naissant répandait à peine sa lumière sur les cimes des montagnes, lorsque surgissent du gouffre profond les chevaux du Soleil, soufflant la lumière de leurs naseaux dilatés ${ }^{51}$...

Пeplepyía Periergia, supervacua, et (ut ita dixerim) operositas nimia in loquendo. [28] Quod vitium aut idem, aut certe admodum affine ei, quod $\mu \alpha \varkappa \rho \circ \lambda$ oүíav nominat cum

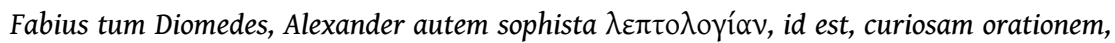
cum sermo cultus gratia longior sit et curiosior, quam oportet. Virgilius: Postera vix 
summos spargebat lumine montes Orta dies, cum primum alto se gurgite tollunt Solis equi lucemque elatis naribus efflant.

\section{prend pour le bien l'apparence du bien ; malheureusement, c'est à qui l'emportera dans ce défaut, à tel point que, aujourd'hui, le pire de tous les défauts est pratiquement le} défaut le plus commun chez tous ${ }^{65}$.

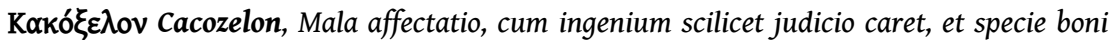
fallitur, infeliciterque aemulatur vitium, ut omnium pessimum, ita hodie omnibus ferme commune.

31 Aschematiston ${ }^{66}$. C'est-à-dire figuration défaillante, lorsque l'énoncé, tombant à plat, est privé de ses figures, lesquelles le feraient briller telles de petites étoiles ${ }^{67}$.

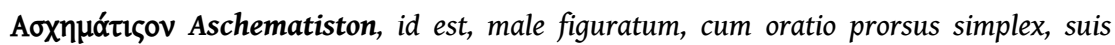
figuris quibus velut stellulis reluceret, caret. 


\section{l'endroit qui lui conviendrait ${ }^{68}$, comme: et nous harcelons des boeufs Les échines de nos} lances retournées. Énéide, livre $9^{69}$.

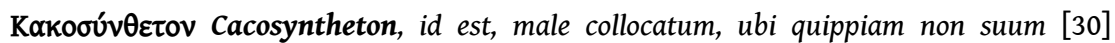
habuerit locum in quo quadret, ut versaque juvencum Terga fatigamus hasta. Aeneid. 9.

Soraismus. Un mélange et un entassement de dialectes d'origines variées chez les Grecs, et chez nous, de termes vernaculaires et latins, propres et impropres, anciens et nouveaux ${ }^{70}$.

$\Sigma \omega$ palouós Soraismos, Miscella quaedam et acervatio ex variis idiomatis apud Graecos, apud nos ex verbis barbaris et latinis, propriis et impropriis, obsoletis et novis.

Et pour ne rien vous cacher, en ce qui concerne ces défauts je ne saurais vous en accorder aucun, non, pas le moindre. Car quoique Virgile fut plus d'une fois audacieux dans ces mêmes défauts, il ne serait cependant pas avisé que vous l'imitiez sur ce point $^{71}$.

Ac ut sis sciens, in his vitiis plane nihil tibi condonarim. Nam quamvis Virgilius semel atque iterum in ipsis audax fuerit, tibi tamen non itidem haec imitari fuerit consultum.

\section{Les fautes relatives à l'incorrection / Barbarum ejusque species}

L'incorrection est un défaut qui tend à ce qu'on pourrait appeler une certaine barbarie $^{72}$.

Les fautes relatives à l'incorrection sont : le barbarisme, la barbarolexie, le solécisme ${ }^{73}$.

Barbarum, vitium quod ad quandam velut barbariem tendit.

Partes sunt hae: Barbarismus, Barbaralexis, Soloecismus.

Barbarisme. Terme fautif qui pèche contre la grammaire de la langue latine, à l'écrit ou à l'oral. Il se produit par addition, soustraction, substitution, transposition : et ce, d'une lettre, d'une syllabe, d'un temps verbal, d'un ton, d'une aspiration ${ }^{74}$. [...]

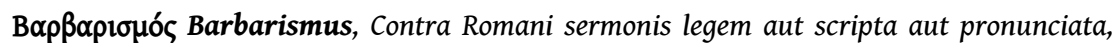
vitiosa dictio. Fit autem additione, detractione, immutatione, transpositione: et id quidem aut literae, aut syllabae, temporis, toni, aspirationis. [...]

Barbarolexie $^{75}$. C'est-à-dire terme incorrect, chaque fois qu'un terme d'une langue étrangère est inséré dans un énoncé latin ${ }^{76}$, comme gaza chez Virgile, terme d'origine perse $^{77}$; et mastruca chez Cicéron, mot sarde ${ }^{78}$.

[31] B $\alpha \rho \beta \alpha \rho \alpha \lambda \varepsilon ́ \xi 1 \varsigma$, id est, Barbara dictio, quoties Romano sermoni peregrinae linguae dictio inseritur, ut gaza apud Maronem, quod est Persicum : et mastruca apud Ciceronem, Sardum vocabulum.

Solécisme. C'est (pour reprendre Asinius Capito, chez Aulu-Gelle) une construction disconvenante et défectueuse ${ }^{79}$, qui se remarque par tous les accidents dans les différentes parties de l'énoncé, quand une partie de l'énoncé est mise à la place d'une autre : un genre à la place d'un genre, un cas à la place d'un cas, un temps, un mode, un nombre, un adverbe à la place d'un autre, une proposition à la place d'une autre ${ }^{80}$. Si cela avait été permis dans les limites de ce livre, j'aurais donné bien volontiers tous les exemples, non pour les imiter mais pour les éviter, ce qui est plus facile quand on les signale à l'attention. À défaut, on peut observer ces fautes par soi-même, ou voir Donat $^{81}$.

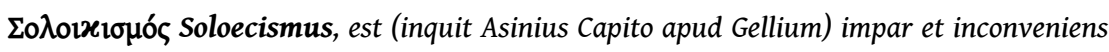
compositura partium orationis, quae per omnia partium orationis accidentia notatur, cum alia orationis pars pro alia ponitur, cum genus [32] pro genere, casus pro casu, tempus pro 
tempore, modus pro modo, numerus pro numero, adverbium pro adverbio, praepositio pro praepositione. Horum omnia exempla, non ut imitareris, sed ut notata minori negotio devitares, oppido quam libens adscripsissem, si per chartae angustiam licuisset. Quare vel ipse observes, vel ex Donato petas licebit ${ }^{82}$.

\section{NOTES}

1. Rodolphus Agricola (1444-1485), De inventione dialectica libri omnes (rédaction c. 1483, $1^{\text {re }}$ éd. 1515), éd. Alard d'Amsterdam («per Alardum Aemstelredamum accuratius emendati et additis annotationibus illustrati»), Cologne, Johann Gymnich, 1539, p. 316 : «Cum sunt autem (ut alio loco diximus) tria, quibus perfecta constet oratio, quae sunt, emendatio sermonis, probabilitas dictionis, et elocutionis ornatus : quorum cum primum grammatice doceat, secundum dialectice, tertium cui tribuam nisi rhetoricae, prorsus non invenio ; [...] perspicuitas solum, compositio cultusque orationis, suus futura sunt labor. ". Pour une présentation d'Agricola, nous renvoyons à la thèse de Ph. Collé (Traduction $d u$ De Inventione dialectica de Rodolphe Agricola, doctorat soutenu à l'Université Grenoble Alpes, 2020). Pour l'établissement du texte et une traduction allemande, nous renvoyons à l'éd. de Lothar Mundt: De Inventione dialectica libri tres, Drei Bücher über die Inventio Dialectica, Tübingen, Max Niemeyer Verlag, 1992 (ici, p. 380).

2. Voir par exemple K. Meerhoff, Entre logique et littérature: autour de Philippe Melanchthon, Orléans, Paradigmes, 2001.

3. Voir P. Mack, A History of Renaissance Rhetoric 1380-1620, Oxford, Oxford University Press, 2011, ch. 10 « Manuals of Tropes and Figures », p. 207.

4. P. Mack, ibid., p. 214.

5. Tabulae de schematibus..., Augsbourg, Philipp Ulhart, 1515 (voir le titre complet infra, dans nos "principes d'édition»). Le texte étant imprimé après le De figurata ratione iudicium de Xystus Betuleius (Sixtus Birken, 1501-1554), il bénéficie d'un titre intérieur qui est (ibid., p.11): De Schematibus et Tropis Petri Mosellani Tabulae.

6. Voir L. D. Green et J. J. Murphy, Renaissance Rhetoric Short Title Catalogue (1 ${ }^{\text {re }}$ éd. J. J. Murphy, 1981), Aldershot, Ashgate, 2006, p. 390-392.

7. Le texte seul: Schemata seu Figurae Petri Mosellani, Nuremberg, Friedrich Peypys, 1527 (éd. due aux soins de Theodorus Reyssmann, 1503-1544) ; à la fin d'un recueil de manuels latins : De Figuris sententiarum ac verborum, Lyon, Sébastien Gryphe, 1540, comprenant les manuels de Rutilius Lupus, d'Aquila Romanus, de Julius Rufinianus, de Bède et de Mosellanus.

8. Tabulae de schematibus et tropis Petri Mosellani. In Rhetorica Philippi Melanchthonis. In Erasmi roterodami libellum de duplici Copia, Cologne, Jean Soter, 1526.

9. Voir http://www.petrus-mosellanus.de/index.htm; U. L. Kremer, « Mosellanus : Humanist zwischen Kirche und Reformation ", Archiv für Reformationsgeschichte, 1982, vol. 73, p. 20-34.

10. Voir M. R. Croci Londoniensis Tabulae graecas literas compendio discere cupientibus..., Leipzig, Valentin Schumann, 1516.

11. Voir par exemple (dans Diomedis vetustissimi ac diligentissimi grammatici emunctum opus nec non Phocae, Prisciani, Capri, Agraetii, Donati, Servii et Sergii aurea opuscula..., Venise, imprimé par les frères Giovanni et Bernardino Rosso de Vellici, 1511 [14 novembre 1511], livre II) l'intitulé du ch. VI (n. p.): «De Schematibus \& Tropis». Rappelons que les intertitres de l'édition Keil de Diomède comme des autres grammairiens latins sont pour la plupart absents des éditions de la Renaissance ; et en particulier pour Donat, dans l'édition de 1511 (ibid., n. p.), l'intertitre général 
concluant le De octavo partibus orationis editio secunda [Ars major] est : « Donatus de Barbarismo ». Du côté des éditions anciennes des grammairiens latins tardifs, Isidore de Séville (c. 560-636) au livre I de ses Etymologiae intitule le chapitre XXVI [XXXV dans l'éd. de 1493] « De schematibus » et le chapitre XXVII [XXXVI] «De tropis » (consulté dans : Isidori Etymologiarum opus. De summo bono, Venise, Boneto Locatello pour Ottaviano Scoto, 1493, n. p.). Pour ce qui est des prédécesseurs immédiats de Mosellanus, Niccolò Perotti intitule une brève section de ses Rudimenta grammatices ( $1^{\text {re }}$ éd. Rome, Konrad Sweynheym et Arnold Pannartz, 1473, s.p.) «De figuris»; et Johannes Cochlaeus une des grandes sous-sections de son Quadrivium grammatices (Nuremberg, Stuchs, 1511, f. LXI) « De triplicibus grammaticae figuris ».

12. Sans préjuger de la connaissance que le Moyen Âge et la première Renaissance pouvaient avoir de leurs versions manuscrites, il est à noter que les premières éditions imprimées des ouvrages de Rutilius Lupus, Aquila Romanus et Bède le Vénérable sont ultérieures (même si après coup des recueils mettront Mosellanus à la suite des rhéteurs latins : voir la référence donnée supra note 7). Pour Rutilius Lupus (Schemata dianoeas et Schemata lexeos) et Aquila Romanus (sans titre), voir P. Rutilius et Aquila Romanus. Antiquissimi auctores, Venise, Niccolò Zoppini, 1519 ; pour Bède le Vénérable (de Schemate et tropo), voir Diomedes grammaticus, aliique decem \& nouem authores... Additis sex aliis clarissimis authoribus, nec non duobus alphabeticis repertoriis, \& aliis multis ad utilitatm facientibus, qua in aliis hactenus impraessis non reperies, Venise, Cesar Arrivabene, 1522. Quant au De figuris de Despautère, ses deux premières éditions sont de 1519 (Paris, Josse Bade) et 1520 (Gand, Pierre de Kaysere).

13. Pour une confrontation de cette division à celles de Donat et Diomède, voir infra note 29.

14. Voir J.-C. Saladin, La Bataille du grec à la Renaissance, Paris, Les Belles Lettres, 2000.

15. Sur le latin «langue» de la rhétorique d'ancien régime, voir notre article: « Narratio / Narration? La rhétorique et la langue française ", Littératures classiques 2018/2, n 96, Les intraduisibles du vocabulaire critique (XVI ${ }^{e}$-XVIII ${ }^{e}$ siècles), p. 85-97.

16. Voir cet intitulé du chapitre réservé aux fautes du discours chez Johannes Cochlaeus (Quadrivium grammatices, op. cit., f. LXIIIr: "De figuris viciosis licentia permissis» («Des figures défectueuses permises par licence »). Sur la proximité entre vices du discours et figures de la poésie chez les grammariens latins, voir M. Baratin et Fr. Desbordes, « La troisième partie de l'ars grammatica ", Historiographia Linguistica, numéro dirigé par D. J. Taylor, 1986, 13, p. 215-240. Pour un relevé du motif chez Quintilien, Donat, Diomède et Mosellanus, voir infra notes 30, 53 et 71 .

17. Voir infra note 31.

18. L. Carbone, Divinus Orator vel de Rhetorica divina libri septem, Venise, Societas minima, 1595, L. V, chap. XXII, p. 331-336.

19. Voir V. Erythraeus (1521-1576), Liber unus de Vitiis orationis dans le recueil intitulé : Valentini Erythraei Lindaviensis de Grammaticorum figuris, tam singulorum, quam constructorum verborum, et de periodis, libri quatuor, correcti, et aucti. Item, liber unus, de vitiis orationis, antehac nunquam editus, eodem Erythraeo authore. Adiectum est iudicium Ioachimi Camerarii de Orthographia, Strasbourg, Christian Müller, 1561, p. 343-520.

20. Voir le commentaire de Veltkirch au chapitre VIII du Livre I, dans D. Erasmi Roterodami de duplici Copia Verborum ac rerum, Libri duo. Una cum Commentariis M. Veltkirchii Oratoriae professoris in Schola Vittenbergensi, jam recens natis ac aeditis, Haguenau, Pierre Brubach, 1534, f. 10v-15r. Sur Veltkirch, alias Velcurio [Velcurius] alias Johann Toltz von Veltkirch [Feldkirch] alias Johannes Bernhard [Bernhardi], 1490-1534 : voir K. H. Burmeister, « Ein Kommentar zur Copia Verborum des Erasmus von Rotterdam von Johannes Bernhardi », Montfort 22 (1970), p. 272-282.

21. Voir Veltkich, op. cit., f. 13r, 14r, les fautes $\mathrm{n}^{\circ} 16,17$ et 23 . Ces trois termes sont inconnus des auteurs anciens, qu'ils soient grecs ou latins, mais réapparaissent régulièrement après 1534, sous des graphies translittérées souvent approximatives.

22. Sur ces trois fautes chez Mosellanus, voir infra notes 38 et 50. 
23. Défaut modélisé sur le genre de discours asianus, oriental : voir Quintilien, Institution oratoire, 12.10.1-40.

24. Voir R. Sherry, A Treatise of Schemes and Tropes, Londres, John Day, 1550 ; H. Peacham, The Garden of Eloquence conteyning the figures of grammer and rhetorick..., Londres, H. Jackson, 1577 ; voir également J. Susenbrotus, Epitome troporum ac schematum et grammaticorum et rhetorum..., Zurich, Cristoph Froschauer, 1540.

25. Pour ces listes étendues de défauts du discours, par ordre chronologique voir: J. Rivius [1500-1553], De dialectici libri VI, de rhetorica libri II, de periodis libellus I, Lepizig, Nicolaus Wolrab, 1539, n. p., 27 fautes répertoriées au L. II du de rhetorica, (c'est une reprise de Veltkirch: pas d'édition antérieure de l'ouvrage - P. Mack, à la suite de Green et Murphy, lui attribuant par erreur un ouvrage de Ringelberg publié en 1531, Rhetoricae, quae ad eam spectant dans Joachimi Fortii Ringelbergii Andoverpiani opera, quae proxima pagina enumerantur, Lyon, Gryphe, où de toute façon ne figure pas de liste consacrée aux fautes du discours). Voir également G. Wibotius [Joris Wibo, c. 1530-1576], Compendium rhetorices..., Anvers, Jean Verwithagen, 1556; C. Valerius [Kornelius Wouters, 1512-1578], In universam bene dicendi rationem tabula, summam artis rhetoricae complectens..., Louvain, héritiers Arnold Birckmann, 1557; V. Erythraeus, Liber unus de Vitiis orationis, 1561, op. cit. ; etc.

26. Luis de Granada, Ecclesiasticae rhetoricae, sive de ratione concionandi libri sex..., Lisbonne, António Riberio, 1576 ; trad. fr. Louis de Grenade, La Rhétorique de l'Église ou l'Éloquence des prédicateurs, trad. N.-J. Binet, Paris, Jean Villette, 1698.

27. Ch. Pajot, Tyrocinium eloquentiae sive rhetorica nova et facilitor, $1^{\text {re }}$ éd. Blois, F. de la Saugère, 1646 ; s. d. (« ultima editio »), Venise-Bassano, A. Remondini [1708], L. IV, ch. 6 « Elocutionis vitia », p. 355-357.

28. C. Soarez, De arte rhetorica libri tres, ex Aristotele, Cicerone \& Quinctiliano praecipue deprompti (1 ${ }^{\text {re }}$ éd. Cologne, 1557), Turin, Zapata, 1686 ; F. Pomey, Novus candidatus rhetoricae..., Lyon, Molin, 1667 ; J. de Jouvancy, Candidatus rhetoricae olim a Franc. Pomey e Societate JESU digestus In hac editione novissima auctus, emendatus \& perpolitus, Rome, de Martiis, 1710 (L'Élève de rhétorique, éd. de 1712, sous la dir. de F. Goyet et D. Denis, Paris, Classiques Garnier, 2020).

29. Traité en trois parties: la première recense les figures de mots (sous trois chefs: figurae dictionis, locutionis, constructionis), la deuxième les défauts, la troisième les qualités (dont l'ornatus, produit par l'usage des tropes). Mosellanus reprend ici trois sections consécutives de Diomède au L. II de son Ars grammatica (resp. p. 443, 449, 456) : " De schematibus ", "De vitiis orationis ", "De virtutibus orationis ».

30. Cette définition est le propre de Mosellanus. Les grammairiens latins du $\mathrm{IV}^{\mathrm{e}}$ siècle (Charisius, Aelius Donat, Diomède : références données supra en tête de la section "Édition ») passent directement à la liste des défauts. Les rhétoriciens antérieurs (Démétrius, l'auteur de la Rhétorique à Herennius, Quintilien, Longin) commencent par définir des vertus (vertus du discours: Quintilien; vertus des styles: Démétrius, Rhétorique à Herennius, Longin) pour appréhender en termes de manquements (par défaut ou par excès) les vices de l'éloquence.

À la suite des remarques de rhéteurs antiques sur les différences et les ressemblances entre lexis oratoire et lexis poétique (voir déjà Aristote, Rhétorique, 3.1, 1414a20 sq. et surtout Denys d'Halicarnasse, La composition stylistique, 6.24-25), Mosellanus quant à lui introduit ici même et à la fin des deux premières sous-sections l'idée d'une différence d'appréciation concernant les fautes selon qu'il s'agit de prose ou poésie: ce qui est beauté ici devient là error (erreur de jugement : le judicium règne sur la prudence stylistique de l'orateur, sa capacité d'adaptation aux circonstances stylistiques, en opposition à l'audacia du poète à laquelle il sera fait allusion en clôture). Voir infra notes 53 et 71.

Pour un point de vue semblable concernant exclusivement certains types de barbarismes, voir Quintilien (1.5.11, p. 20) : " haec apud scriptores carminum aut venia digna aut etiam laude duci ", " ces fautes sont excusables chez les écrivains en vers, et doivent même quelquefois être regardées 
comme des beautés ». Repris par Diomède, p. 455-456: «sed hoc vitium in soluta oratione nomen suum retinet, ceterum apud poetas metaplasmus vocatur ", " mais ce défaut conserve son nom dans l'énoncé en prose, autrement il est appelé métaplasme chez les poètes »; même texte chez Charisius, p. 265 ; voir également Donat, p. 392 : « in poemate metaplasmus, itemque in nostra loquella barbarismus ", "c'est dans un poème un métaplasme et dans notre langue un barbarisme ».

31. Quintilien oppose aux trois vertus que sont la correction (emendatio), la clarté (perspicuitas) et l'ornement (ornatus), respectivement les formes d'incorrection (en 1.5, partiellement repris en 8.1), les formes d'obscurité (en 8.2) et les formes qui contreviennent à l'ornement (en 8.3). Charisius et Donat ignorent cette tripartition. Diomède la reprend dans son art grammatical, littéralement si l'on suit l'édition Keil (p. 449): «Vitia orationis generalia sunt tria, obscurum, inornatum, barbarum" (nous soulignons). Mais les éditions de la Renaissance donnent, pour Diomède, inordinatum et non inornatum. Voir par exemple Diomedis vetustissimi..., op. cit., l. II, n. p. : «Vitia orationis generalia sunt tria : obscurum, inordinatum, barbarum ». Mosellanus suit ici à la lettre le Diomède de la Renaissance : non pas inornatum, contraire à l'ornatus, mais inordinatum, contraire à l'ordo, « désordonné ».

32. "Vel verborum vel structurae vitio » : Mosellanus synthétise ici le plan qu'adopte Quintilien en 8.2, sans l'annoncer ou le récapituler: le chapitre 8.2 commence en effet par analyser les cas d'obscurité in verbis, dans les termes, de 8.2.1 à 8.2.13; puis après une annonce en 8.2.14 (p. 284 : "Plus tamen est obscuritatis in contextu et continuatione sermonis », "Toutefois l'obscurité est plus grande dans une longue suite de mots, c'est-à-dire dans la contexture du discours »), il recense les fautes relatives à l'obscurité dans l'arrangement des mots de 8.2.14 à 8.2.24. Diomède quant à lui commence directement son paragraphe sur l'obscurum par la liste des fautes. Puis il ajoute un développement sur les ambiguïtés du sens, lesquelles sembleraient devoir relever de l'obscurité in res plus qu'in verbis ou qu'in contextu [verborum].

33. Les fautes relatives à l'obscurité sont expliquées et exemplifiées mais ne sont généralement pas nommées par Quintilien en 8.2. Quintilien identifie, pour l'obscurité in verbis, le mot obscène, le mot impropre (qu'il nomme acyron), les mots qui sortent de l'ordinaire (archaïsmes, termes de métier, mots dialectaux) et les périphrases compliquées ; pour l'obscurité in contextu, la longueur des phrases, l'enchevêtrement des constructions, les ambiguïtés syntaxiques, l'abondance stérile, la concision excessive, l'excès figural ; le chapitre se conclut sur les cas d'obscurité dans les choses (que l'on pourrait dire in res : allégories, équivoques).

Il est à noter que les fautes dans l'arrangement des mots (in contextu), que Quintilien subordonne donc en 8.2 à l'obscurité, évoquent celles qu'il liste (et pour le coup nomme) dans le chapitre suivant (8.3), consacré à l'inornatum, ou rappellent celles qu'il a regroupées dans son chapitre sur les défauts liés à la dispositio en 7.9 ; de même les fautes liées au trouble du sens (in res) seront précisées dans le chapitre consacré aux tropes (8.6).

D'où un important travail de récupération effectué dans l'ars grammatica de Diomède, dont s'inspirera directement Mosellanus. Concernant l'obscurité, Diomède rassemble huit fautes: l'acyrologia (ou acyron: Quintilien, 8.2.3), le pléonasme (8.3.53), la périssologie (8.6.61), la macrologie (8.3.53), l'amphibologie (7.9), la tautologie (8.3.50), l'ellipse (8.3.50), l'énigme (8.6).

Par rapport à Diomède, Mosellanus fusionne la macrologie avec la périssologie, il ajoute (en les reprenant de Quintilien, 8.3.52 et 55) l'homologie et la périergie, et il omet tous les cas relevant de l'obscurité dans les choses (énigmes). Surtout il réordonne la liste, en commençant par les obscurités in verbis (acyron, pléonasme, périssologie) et en poursuivant avec les obscurités in contextu (tautologie, homologie, amphibologie, ellipse, périergie).

34. À comparer avec: Quintilien (8.2.3, p. 284 : «Id apud nos improprium, ö́kvpov apud Graecos uocatur ", "C'est ce que nous appelons terme impropre, en grec acyron»), Charisius, p. 270 et Donat, p. 394 (« Acyroligia est dictio impropria », "L'acyrologie est un terme impropre»); enfin Diomède (p.449: «Acyrologia est dictio minus convenienter elata, vel non propriis dictionibus obscurata sententia», "L'acyrologie est un terme exprimé sans aucune convenance ou une expression 
obscurcie par des termes impropres»). - «Comme un épais brouillard»: litt., " comme un nuage ». Cf. Éraseme, adage Per nebulas (263, I, III, 63).

35. Térence, Andrienne 395 (trad. H. Clouard, Garnier, s. d.). Sperare pour timere : exemple d'acyron chez Quintilien (8.2.3, p. 284, avec appui sur Virgile, Énéide, 4.419 : «tantum sperare dolorem », litt. " espérer une si grande douleur ", d'après la trad. de A.-M. Boxus et J. Poucet, L'Énéide louvaniste, 1998-2013, en ligne sur les site de la Bibliotheca Classica Selecta et d'Itinera electronica). Repris avec même référence à Virgile par Charisius (p. 270), Donat (p. 394) et Diomède (p. 449). Mosellanus garde l'acyron sur « sperare », mais l'illustre avec un exemple qui lui est propre.

36. Définition et premier exemple repris directement de: Quintilien (8.3.53., p. 292), "Est et pleonasmos vitium, cum supervacuis verbis oratio oneratur : ego oculis meis vidi, sat est enim vidi", «Le pléonasme est aussi un défaut, quand il surcharge l'oraison de mots superflus, si, par exemple, on disait : Je l'ai vu, moi, de mes yeux; car il suffit de dire : J'ai vu». Autre définition, sans ce premier exemple, chez Charisius et Diomède (Charisius p. 271 et Diomède p. 449 : « est sententia verbo plus quam necesse est abundans", "c'est une expression qui est plus abondante que nécessaire en raison d'un terme ») ainsi que chez Donat (p. 395 : «est adjectio verbi supervacui ad plenam significationem ", " c'est l'ajout d'un mot superflu à la signification pleine et entière »).

37. Virgile, Énéide, 1.614, op. cit. Exemple repris de Charisius, Donat et Diomède.

38. Le terme apparaît, sans définition, en Quintilien 8.6.61 (ainsi qu'en 4.2.43). L'exemple retenu étant celui qui illustre la macrologie chez Quintilien (8.3.53, voir infra note 50), Charisius, Donat et Diomède, il est tentant de confronter la définition que Mosellanus donne de la périssologie, d'une part aux définitions antiques de la périssologie et d'autre part à celles de la macrologie.

Les définitions de la périssologie chez Charisius, Donat et Diomède sont très proches et pointent vers la redondance: «ajout superflu de beaucoup de mots» (Charisius, p. 271: «multorum verborum adjectio supervacua»), "ajout superflu de mots sans aucune force dans la pensée » (Donat, p. 395 : « supervacua verborum adjectio sine ulla vi rerum »), « ajout superflu de beaucoup de mots sans aucune force dans la pensée » (Diomède, p. 449 : « multorum verborum adjecto supervacua sine ulla vi rerum »).

La macrologie quant à elle oriente plus vers la prolixité, l'abondance de détails qui, sans être répétitifs, ne sont pas nécessaires : «énoncé plus long qu'il convient» chez Quintilien (8.3.53, p. 292 : «longior quam oportet sermo »), «long énoncé sans art» pour Charisius (p. 271 : «oratio longa sine cultu»), "expression longue comprenant des choses non nécessaires» pour Donat (p. 395 : « longa sententia res non necessarias conprehendens »), « énoncé trop long et sans art » pour Diomède (p. 449 : « oratio sine cultu nimium longa »).

En insistant sur la longueur (longum) et non sur le superflu (supervacuum), Mosellanus tire la périssologie (faute dans les mots) vers la macrologie (faute dans l'arrangement des mots) et la met ainsi en position de transition entre les fautes générant une obscurité in verbis et celles qui entraînent une obscurité in contextu.

39. Fragment de Tite-Live transmis par Quintilien, lequel le cite pour illustrer le défaut nommé

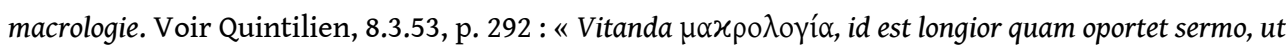
apud T. Liuium: legati non impetrata pace retro domum, unde venerant, abierunt. " "Évitons aussi la macrologie, c'est-à-dire un énoncé plus long qu'il convient, comme dans ce passage de Tite-Live: Les ambassadeurs, n'ayant pu obtenir la paix, s'en retournèrent chez eux, d'où ils étaient venus.»

40. Mosellanus reprend la définition littérale de Quintilien et paraphrase son exemple. Voir Quintilien, 8.3.50, p. 292 : « ... tautologia, id est ejusdem verbi aut sermonis iteratio [...] ; in quod saepe incidit etiam Cicero securus tam parvae observationis, sicut hoc loco: non solum igitur illud judicium judicii simile, judices, non fuit » « ... la tautologie, c'est-à-dire la répétition d'un même mot ou d'un même énoncé [...]; Cicéron lui-même y tombe souvent, n'ayant pas daigné s'assujettir à un si petit détail, comme lorsqu'il dit: Non seulement donc, juges, ce jugement n'a rien qui ressemble à un jugement ». 
Autres définitions (et autres exemples) chez les grammairiens latins : « répétition du même mot ou d'un mot avec même signification » pour Charisius (p. 271 : « ejusdem vel idem significantis verbi iteratio ») ; "répétition défectueuse d'un même terme » pour Donat (p. 395 : « ejusdem dictionis repetitio vitiosa»), "répétition superflue d'un même terme dans une même expression » pour Diomède (p. 450 : « ejusdem dictionis in eadem sententia superevacua repetitio »).

41. Cicéron, Pro Cluentio, 96.

42. Terme et définition repris littéralement de Quintilien, 8.3.52 (selon le texte des éditions de la

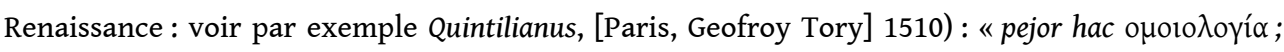
quae nulla varietatis gratia levat taedium atque est tota coloris unius", " pire est l'homologie, laquelle provoque l'ennui par son absence complète de variété, étant au contraire tout entière d'une seule couleur». Les éditions actuelles donnent "pejor hac homoioeideia» (voir par exemple l'éd. J. Cousin, Paris, Les Belles Lettres, t. V, 1978: Cousin attribue dans ses variantes la leçon homoeologia à A (= le ms Ambrosianus lat. E 153 sup.). Enfin, l'homologie est absente des listes des trois grammairiens latins.

43. Quintilien non plus ne donne pas d'exemple. Pour un exemple ultérieur, voir J. Goulu, Seconde partie des Lettres de Phyllarque à Ariste (1628), $3^{\mathrm{e}}$ éd., Paris, Vve Nicolas Buon, 1629, Lettre VIII, « De la manière qu'il faut varier son style selon les règles de la rhétorique », p. 115 sq. : «...[le défaut] que les Grecs appellent homoiologia, c'est-à-dire quand la tissure du discours est toujours d'une même couleur, d'une même façon, et sans aucune variété qui contente l'esprit et qui empêche qu'on ne s'ennuie. [...] Ceux qui savent ce que je veux dire [...] découvriront incontinent dans les écrits de l'auteur des lettres [Guez de Balzac] ce vice qui s'y rencontre quasi perpétuellement. Il n'y a nulle variété en son style, c'est toujours une même manière, une même façon, une même cadence [...]. » Nous renvoyons à la suite de la Lettre pour de larges extraits du style incriminé.

44. Quintilien envisage au chapitre 9 du livre 7 les différents cas d'amphibologie (qu'il définit simplement par l'ambiguïté, quand un mot ou une expression signifient plusieurs choses : voir 7.9.1) : pour l'ambiguïté dans la construction (7.9.6, p. 275 : « in cunjunctis », « dans la liaison [des mots]»), Quintilien ne donne pas de définition mais l'illustre précisément par l'oracle d'Apollon, exemple que reprendront Charisius et Diomède avant Mosellanus. En ce qui concerne la définition proprement dite, pour Charisius l'amphibologie est « un terme ou une expression qui a deux significations» (p.271: «dictio sententiave dubiae significationis»); pour Donat, «une ambiguïté terminologique » (p. 395 : «ambiguitas dictionis ») ; pour Diomède, "une expression disposée de manière ambiguë en raison d'un défaut dans l'arrangement des termes» (p. 450 : " vitio compositionis in ambiguo posita sententia »).

45. Litt. : "J'affirme, Éacide, toi les Romains pouvoir vaincre »; oracle d'Apollon rapporté par le poète Ennius, selon Cicéron (De Divinatione, 2.56.115, trad. C. Appuhn, 1936).

46. Définition reprise de Quintilien (8.3.50, éd. 1510, op. cit.) : « Vitari debet et $\mu \varepsilon i ́ \omega \sigma \mathrm{l}$, cum sermoni deest aliquid, quo minus plenus sit ", " On doit aussi éviter la meiôsis, quand il manque quelque chose à l'énoncé, qui fait qu'il est moins plein » (les éditions actuelles donnent «Vitari <...> et elleipsis, cum sermoni deest » : voir l'éd. Cousin, 1978, op. cit.). Autres définitions chez Charisius (p. 271 : "sententia verbo minor quam necesse est ", " une expression où manque un terme nécessaire »), chez Donat (p. 395 : "defectus quidam necessariae dictionis, quam desiderata praecisa sententia », « un manque concernant un terme nécessaire que demanderait une expression précise »), et chez Diomède (p. 450, avec reprise partielle de Donat: «necessaria dictione fraudata sententia, defectus quidam necessariae dictionis quam desiderat praecisa sententia », " une expression où l'on a soustrait un terme nécessaire, un manque concernant un terme nécessaire que demanderait une expression précise »).

47. Virgile, Énéide, op. cit., 1.2. Exemple repris de Diomède.

48. Térence, L'Eunuque, 65 (trad. É. Chambry, Garnier, 1932). Exemple propre à Mosellanus.

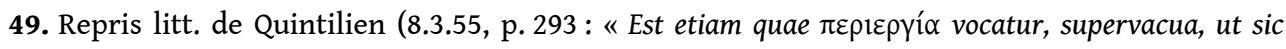
dixerim, operositas »). L'incise ut sic dixerim (" pour ainsi dire», chez Quintilien) ou ut ita dixerim 
chez Mosellanus, revient à excuser l'emploi du substantif inhabituel d'operositas, unique occurrence en latin classique : litt. la « laboriosité ». Les grammairiens latins ne font pas mention de la périergie.

50. Même texte dans l'édition de 1527. En revanche, certaines des éditions revues par Georg Major (où l'ouvrage de Mosellanus est associé aux tables de Mélanchton et d'Érasme, $1^{\text {re }}$ éd. 1526)

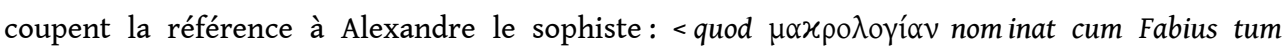
Diomedes, cum sermo cultus gratia longior sit quam oportet $>$.

Sur la macrologie, voir Quintilien, 8.3.53, p. 292 : « longior quam oportet sermo », "énoncé plus long qu'il ne convient »; Diomède p. 449 : « oratio sine cultu nimium longa ", « énoncé trop long et sans art».

Sur la leptologie, figure de la minutie et du détail, voir le De figuris d'Alexandre le Sophiste [Alexander Numenius ou Alexandros fils de Noumenios, II $^{\mathrm{e}}$ siècle de notre ère] dans les Rhetores graeci (éd. Ch. Walz, t. VIII, Stuttgart, Tübingen, Londres, Paris, 1832, p.441-442) : la figure de la leptologie demande un travail précis ( $\alpha \kappa_{\kappa} i ́ \beta \eta$ : exactus dans la trad. de N. Conti, voir réf. ci-après) et minutieux ( $\lambda_{\varepsilon \pi \tau \eta}$ : minutus chez N.Conti, curiosus au texte ci-dessus de Mosellanus). Éd. princeps : Rhetores graeci, Venise, Alde, vol. 1, 1508, Alexandri sophistae de figuris sensus et dictionis, p. 578 ; trad. latine de Natale Conti, Alexandri Sophistae De figuris sententiarum ac elocutionum, Venise, Santo Guerrino, 1557, p. 13. Pour une insistance sur la leptologie comme art de détailler, voir également Cassiodore, Expositio Psalmorum II, 8 (éd. du Xve siècle : Cassiodori... in Psalterium Expositio, Bâle, Joham Amerbach, 1491, n. p., sur le psaume LI) : « quando res singulae minutatim ac subtiliter indicantur »» (" quand les choses sont mentionnées une par une par le menu et avec précision »).

Mosellanus a par deux reprises réutilisé le fonds définitionnel de la macrologie : il en a récupéré un des exemples traditionnels pour illustrer la périssologie (voir supra note 38) et il l'assimile à présent à la périergie. Trois sèmes circulent entre la périssologie, la macrologie, la périergie et la leptologie : la longueur, la superfluité, le raffinement. La periergia cumule ici les défauts de la périssologie et de la macrologie (superfluité, longueur), tout en ayant en propre le raffinement, l'excès de détail (l'operositas de Quintilien, 8.3.55, p.293: contrairement, d'ailleurs, à la macrologie chez Diomède, fruit d'une absence d'art, « sine cultu », p. 449).

51. Virgile, Énéide, op. cit., 12.113-115. Exemple repris à Diomède (sous l'entrée macrologie : p. 449). 52. Pour les différences entre la liste de Diomède et celle de Mosellanus, voir supra note 33. Bien des défauts que Mosellanus a classés sous l'obscurité relèvent uniquement ou également du manquement à l'ornatus pour Quintilien (8.3): en particulier l'ellipse (Quintilien la nomme meiôsis : voir note 46), la tautologie, l'homologie, la macrologie, le pléonasme, la périergie. Comme opérateurs d'obscurité, deux des fautes relevées par Mosellanus posent problème (fautes qui sont précisément absentes des défauts relatifs à l'obscurité chez les grammairiens latins du $\mathrm{IV}^{\mathrm{e}}$ siècle), l'homologie ou uniformité et la périergie ou enflure : on ne voit pas en quoi elles pèchent contre la clarté. Les sept autres défauts en revanche (l'impropriété, le pléonasme, la périssologie, que Mosellanus fait tendre vers la longueur excessive, la tautologie, l'amphibologie et l'ellipse) sont d'évidence des facteurs d'obscurité.

53. La dernière phrase est absente des éditions des Tabulae dues à Georg Major. C'est là un rappel de l'incipit, qui sera une nouvelle fois repris en fin de chapitre : voir supra note 30 et infra note 71.

54. Inordinatum: litt., qui a un défaut d'ordre. Pas de définition générale équivalente chez Diomède, qui donne directement la liste des fautes. Si Mosellanus éprouve la nécessité d'ajouter le défaut de dignitas, c'est en raison de l'inadéquation entre l'inordinatum, que Mosellanus reprend aux éditions de Diomède telles qu'établies par la Renaissance (voir supra, note 31), et les effets de sens liés aux fautes qu'il recouvre (l'obscénité, la platitude, l'affectation, la bigarrure...), lesquelles ne pèchent pas contre l'ordo mais contre l'ornatus. Le mot de dignitas tient en effet, dans la terminologie de la Rhétorique à Herennius, la place que tient l'ornatus dans le De Oratore, et, à sa suite, chez Quintilien. Voir Rhétorique à Herennius (IV, 18, éd. Achard, Paris, Les Belles Lettres, 
1994, p. 148) : "Dignitas est quae reddit ornatam orationem varietate distinguens », "Donner de la beauté au style (dignitas), c'est orner le discours en le relevant par la variété des figures.» La dignitas se trouve aussi chez Cicéron, mais plus discrètement (voir par exemple De Oratore, 1.142, trad. E. Courbaud, 1922: " ...ad extremum agere cum dignitate et venustate », "...finalement mettre en œuvre < les arguments > avec dignité et grâce»). Rappelons que Quintilien 8.3. place précisément ces fautes sous le chapitre des manquements à l'ornement.

55. Mosellanus construit sa liste à partir de Diomède (comme l'indique l'ordre des items) mais en la réinterprétant au prisme d'un retour à Quintilien. Chez Diomède, relèvent de l'inordinatum (dans les éditions de la Renaissance) ou de l'inornatum (dans les éditions actuelles) : la tapinose, l'eschrologie, le cacemphaton, la cacozélie, le cacosyntheton. Quintilien recense dans les fautes qui contreviennent à l'ornatus des fautes également impliquées dans l'obscurité, d'où une liste plus longue (8.3) : le cacemphaton, l'ellipse, la tautologie, l'homologie, la macrologie, le pléonasme, la périergie, la cacozélie, l'anoiconometon, l'aschematiston, le cacosyntheton et le koinismos (ou soraismus / soraismos, selon les éditions, voir infra note 70).

56. É. Littré, Dictionnaire de la langue française (1872-1877) : «Figure de rhétorique, plus connue sous le nom d'exténuation, litote, euphémisme ».

57. Définition et exemple repris de Quintilien, 8.3.48, p. 292 : « Deformitati proximum est humilitatis vitium ( $\tau \alpha \pi \varepsilon i ́ v \omega \sigma l v$ uocant), qua rei magnitudo uel dignitas minuitur, ut saxea est verruca in summo montis vertice "; « Après l'obscénité vient la bassesse des termes, tapinose, quand, par exemple, ils ne répondent pas à l'importance ou à la dignité des choses, comme, une verrue de pierre pour le sommet d'une montagne». Autre paraphrase (et autres exemples) chez Charisius (p. 270 : «rei magnae humilis expositio ", " exposition en style bas d'une grande chose»), chez Donat (p. 395 : "humilitas rei magnae non id agente sententia», "l'abaissement d'une grande chose par une expression qui ne traduit pas cela») et chez Diomède (p. 450 : «contra dignitatem magnae rei humilis expositio", "exposition en style bas d'une grande chose qui va à l'encontre de sa dignité »).

58. Voir Aulu-Gelle, Nuits attiques, 3.7.6 (d'après la trad. de J.-P. Charpentier et M. Blanchet, Paris, Garnier, 1919) : "Censeo, inquit, si rem seruare vis, faciundum, ut quadringentos aliquos milites ad verrucam illam - sic enim Cato locum editum asperumque appellat... " «Si tu veux sauver l'armée, ajouta-t-il, je pense qu'il est à propos qu'on envoie quatre cents soldats vers cette verrue (c'est ainsi que M. Caton désigne les lieux élevés et de difficile accès)... » Mosellanus a donné une série de notes critiques sur les Nuits attiques (publication posthume: Annotationes Petri Mosellani protogensis in clarissimas Auli Gellii Noctes atticas, Bâle, Johann Bebel, 1526).

59. Mosellanus assimile ici le cacemphaton (litt., "d'apparence vicieuse ») et l'eschrologie (ou équivoque obscène), puis en distingue deux cas (le mot obscène, l'enchaînement syllabique obscène).

Chez Quintilien, on ne trouve que le cacemphaton, avec même distinction entre mots et liaison syllabique (8.3.44-47) et ajout d'un troisième cas propre au latin (obscénité par division syllabique). Mosellanus ne reprend aucun des exemples de Quintilien. Chez Charisius, on ne trouve également que le cacemphaton, avec même distinction des deux cas (le mot seul, les syllabes de deux mots en composition : p. 270) et exemples autres. Chez Donat, même distinction (p. 395) et deux exemples (Andrienne 933 et Énéide 1.193) que reprend Mosellanus (voir notes ciaprès).

Diomède quant à lui distingue l'entrée cacemphaton et l'entrée aeschrologia. La définition qu'il donne de l'eschrologie (p. 450) est la même que celle que l'on trouve pour le cacemphaton chez Quintilien, Charisius et Donat : même distinction entre mot obscène en lui-même (exemple repris à Quintilien et Charisius, illustrant chez eux le premier cas de cacemphaton: "ductare", «branler ») et liaison syllabique obscène, avec plusieurs exemples dont notre Énéide 1.193. Quant au cacemphaton, il y voit « un soupçon obscène en raison d'un défaut d'arrangement [des mots] » (Diomède, p. 451 : "vitio compositionis inverecunda suspitio ») et l'illustre par les deux premiers 
exemples que nous trouvons ici chez Mosellanus pour imager le cacemphaton sur un seul mot (Énéide 6.406 et Andrienne 933).

60. Virgile, Énéide, op. cit., 6.406 (exemple repris de Diomède). Ramum: litt., le rameau, un des termes pour désigner le pénis.

61. Andrienne 933, nous traduisons (litt., «dresse tes oreilles »). Cité par Érasme dans l'adage «Auribus arrectis » (2156, III, II, 56). Exemple présent chez Charisius et Diomède.

62. Virgile, Énéide, op. cit., 1.193, litt. : « ... et égaler leur nombre au nombre de ses vaisseaux » (exemple repris de Charisius et Diomède). Phonétiquement la séquence «cum navibus » peut se lire « $c u / n a /$ uibus», où l'on reconnaît cunna, variante tardive de cunnus, l'un des termes pour désigner la vulve : équivoque analogue à celle donnée par Quintilien (8.3.45, repris de Cicéron, Orator, 154), «cum notis" pouvant s'entendre "cunnotis », sur cunnus). Pour revenir au texte de Virgile et rendre en français un équivalent approchant, il faudrait reprendre la séquence des vers 1.192-194 sur la chasse aux cerfs d'Énée, littéralement « ...avant d'avoir, victorieux, mis à terre sept bêtes énormes et égaler leur nombre au nombre de ses vaisseaux », et imaginer la transposition suivante (on nous permettra de mettre en italiques l'enchaînement obscène) : « ... avant que la victoire ne l'eût fait mettre à terre sept bêtes énormes et ne le vit égaler leur nombre au nombre de ses vaisseaux ». Dans les éditions des Tabulae dues à Georg Major, manque le dernier groupe nominal : et fortasse non hujus seculi.

63. Terme attesté dans la langue des $\mathrm{XVII}^{\mathrm{e}}$ et $\mathrm{XVIII}$ e siècles, à partir du mot (latin) cacozelia attesté chez Sénèque le rhéteur puis Quintilien (2.3.9 et 8.6.73). Voir par exemple J. de Mairet, La Silvanire, « Préface », dans Théâtre du XVII , Paris, Gallimard, « Bibliothèque de la Pléiade », 1975, p. 488: "cette importune et vicieuse affectation de pointes et d'antithèses, qu'on appelle cacozélie ».

64. Affectatio : affectation, imitation. En français, le terme étant toujours négatif, on pourrait se passer de l'adjectif et traduire mala affectatio par affectation. C'est ce que fait l'abbé Gedoyn dans sa traduction du passage de Quintilien : il commence par "mauvaise affectation ", puis rend le «Denique cacozelon» par «En un mot, on appelle affectation» (Quintilien, De l'institution de l'orateur, Paris, Grégoire Dupuis, 1718, p. 516). Jean Cousin dans son édition de Quintilien rend mala affectatio par « la recherche malsaine de l'originalité » (op. cit., t. V, p. 76).

65. Repris litt. de Quintilien, 8.3.56, p. 293 : « mala adfectatio ", " quotiens ingenium judicio caret et specie boni fallitur, omnium in eloquentia vitiorum pessimum » (" une affectation vicieuse ", " chaque fois que l'ingéniosité est dépourvue de bon sens et prend pour le bien l'apparence du bien, le pire de tous les défauts propres à l'éloquence ») - son specie boni fallitur rappelle le decipimur specie recti d'Horace (Art poétique, 25 : «nous sommes abusés par l'apparence du bien : je tâche d'être court, je deviens obscur », etc., trad. F. Villeneuve, Paris, Les Belles Lettres, 2002). Quintilien précise plus longuement les fautes caractérisant un "énoncé corrompu» (ibid.: «corrupta oratio »), « l'impropriété ou la redondance des termes, l'obscurité d'une expression resserrée, une composition brisée, une recherche puérile de mots semblables ou ambigus" (ibid.: "verbis maxime impropriis, redundantibus, compressione obscura, compositione fracta, vocum similium aut ambiguarum puerili captatione »); il ne donne pas d'exemple, renvoyant à un ouvrage (perdu) qu'il a écrit sur le sujet.

Pas de cacozelon chez Charisius et Donat. Pour Diomède, la cacozélie est « un énoncé corrompu par une affectation d'ornement, quand celui-ci ne convient pas à l'énoncé que l'auteur veut ainsi orner; il se produit soit par excès d'art, soit par excès d'enflure» (p. 451 : "per affectationem decoris corrupta sententia, cum eo ipso dedecoretur oratio quo illam voluit auctor ornare. Haec fit aut nimio cultu aut nimio tumore »). Diomède donne un exemple pour chaque cas : pour l'enflure, un fragment poétique non identifié (voir A. S. Hollis, Fragments of Roman Poetry C.60 BC-AD 20, Oxford, Oxford University Press, 2007, p. 416-417) ; pour l'excès d'art, Ovide, Métamorphoses 2.107-109.

66. À la suite du cacozelon, Quintilien mentionne trois défauts, dont Mosellanus reprend ci-après les deux derniers : l'anoiconometon (ou mauvaise disposition), l'aschematiston et le cacosyntheton. 
Voir Quintilien (8.3.59, p. 293). Les trois grammairiens du $\mathrm{IV}^{\mathrm{e}}$ siècle ne connaissent que le cacosyntheton.

67. La première formule (« male figuratum ») est reprise de Quintilien, 8.3.59, p. 293. L'assimilation des ornements à de petites étoiles rappelle le terme par lequel Cicéron désigne habituellement les figures d'ornement (lumina) - le diminutif stellula est du latin médiéval, et se trouve chez Vivès ou Érasme.

68. Défaut décrit par Quintilien, Charisius, Donat, Diomède. Voir Quintilien, 8.3.59, p. 293 : «male conlocatum "; Charisius, p. 271 et Diomède p. 451 : «indecens structura verborum ", " construction inconvenante des mots »; Donat, p. 395 : «vitiosa compositio dictionum », « composition vicieuse des expressions ".

69. Virgile, Énéide, op. cit., 9.609-610. Exemple présent chez Charisius, Donat, Diomède.

70. Défaut qui clôt la liste des fautes relatives à l'inornatum chez Quintilien et qu'ignorent les grammairiens du IV $\mathrm{V}^{\mathrm{e}}$ siècle. Quintilien le nomme soraismos ou koinismos dans les éditions de la Renaissance (voir l'édition Bade, op. cit., f. cLXvir : au texte on a soraismos, en marge koinismos) ; les éditions actuelles suivent la conjecture de C. Halm : sardismos, qui désignerait le sabir parlé dans la ville de Sardes en Lydie. Quintilien le définit ainsi (8.3.59-60, p. 293, en citant le début de l'Art poétique d'Horace): "un énoncé mélangé de plusieurs dialectes, comme de l'attique avec le dorien, l'éolien, l'ionien ; le même défaut chez nous serait de mêler confusément des expressions sublimes, ou vieilles, ou poétiques, avec des expressions basses, ou neuves, ou vulgaires, et de composer un tout d'éléments divers; ce qui ferait un monstre semblable à celui que décrit Horace au commencement de son Art poétique: Un peintre qui s'aviserait d'ajuster une tête d'homme sur un cou de cheval... » (" quaedam mixta ex varia ratione linguarum oratio, ut si Atticis Dorica et Aeolica et Ionica confundas; cui simile vitium est apud nos si quis sublimia humilibus, vetera nouis, poetica vulgaribus misceat - id enim tale monstrum quale Horatius in prima parte libri de arte poetica fingit: humano capiti cervicem pictor equinam jungere si velit... »).

71. Ce qui était error chez les orateurs ( $c f$. la définition incipitiale du défaut ici même par Mosellanus) est donc audacia pour les poètes. Sur l'audacia de Virgile, voir la signature interne que le poète a inséré dans les deux derniers vers des Géorgiques (4.566-567, trad. E. de Saint-Denis, introduction et notes J. Pigeaud, Paris, Les Belles Lettres, $1^{\text {re }}$ éd. 1998, 2002, nous soulignons) : "[...] carmina qui lusi pastorum audaxque iuuenta, / Tityre, te patulae cecini sub tegmine fagi », " moi qui ai joué des airs bucoliques, et qui, avec l'audace de la jeunesse, t'ai chanté, ô Tityre, sous le couvert d'un large hêtre ». Sur la porosité entre défauts de la lexis oratoire et qualités de la lexis poétique, voir supra notes 30 et 53.

72. Définition par l'étymologie. Pas de définition générale de l'incorrection chez Diomède, lequel recense directement les défauts afférents. Diomède et Mosellanus abordent ces fautes proprement grammaticales à la fin de leur section consacrée aux défauts de l'éloquence. Quintilien les traite dans le livre qu'il consacre à la grammaire (1.5) et y renvoie dans le premier chapitre du livre qu'il consacre aux vices et aux vertus de l'éloquence (8.1). Charisius et Donat mettent enfin le barbarisme et le solécisme en ouverture de leur liste des défauts.

73. Quintilien et les grammairiens latins $d u \mathrm{IV}^{\mathrm{e}}$ siècle n'ont que deux grandes entrées en parallèle concernant les fautes grammaticales: le barbarisme et le solécisme (voir Quintilien, 1.5.5; Charisius, p. 265-270; Donat, p.392-394; Diomède, p.451-456). S'ils mentionnent tous la barbarolexie, c'est comme cas particulier en marge du barbarisme (voir infra note 75).

74. Repris litt. de Diomède (p. 451 : « barbarismus est contra Romani sermonis legem aut scripta aut pronuntiata vitiosa dictio", "barbarismus fit modis principalibus quattuor, adjectione detractione mutatione transmutatione »). Ces quatre opérations reprennent la célèbre « quadripartita ratio » de Quintilien (1.5.38-39 : voir sur ce point l'article de Régis Caruso dans la présente livraison). À comparer avec: Charisius (p. 255 : «oratio vitiosa», «terme fautif»); Donat (p. 392 : «adjectio, detractio, inmutatio, transmutatio, litterae syllabae temporis toni adspirationis »). Mosellanus a sorti de l'item barbarisme, pour l'insérer à un niveau beaucoup plus général, la réflexion que font 
Quintilien et les grammairiens latins sur la différence entre vers et prose concernant ce type de défaut (en prose, barbarisme; en vers, métaplasme : voir supra note 30). Nous ne donnons pas ici la suite du paragraphe de Mosellanus sur le barbarisme, qui est un répertoire des fautes grammaticales latines.

75. Barbaralexis (Mosellanus) : ou barbaros lexis (Charisius et Diomède), barbarolexis (Donat) ; Quintilien le répertorie en tête des différents modes du barbarisme sans lui donner une dénomination spécifique (voir 1.5.8, p. 20). Pour la traduction, on trouve barbarolexie dans le Littré (op. cit. : « Nom du barbarisme de mots »).

76. À comparer avec Quintilien, 1.5.8, p. 20 («Vnum gente, quale sit, si quis Afrum vel Hispanum Latinae orationi nomen inserat ", « le premier [mode], qui naît d'un mot étranger, si, par exemple, on introduit dans le latin un mot africain ou espagnol»); Charisius, p. 265 ( id est barbara dictio : sed hoc vitium inter se differt, quod barbarismus fit in nostra loquella, barbaros lexis in peregrina", " c'est-à-dire terme étranger : mais il y a cette différence, que le barbarisme concerne des mots de notre langue, et la barbarolexie des mots étrangers ») ; Donat, p. 392 ( « in peregrina barbarolexis dicitur ", "sur des mots étrangers, on parlera de barbarolexie »); Diomède p. 451 ("id est barbara dictio. sed hoc vitium inter se differt, quod barbarismus in Latina dictione fit, barbaros autem lexis tota peregrina dictio ", "c'est-à-dire terme étranger : mais il y a cette différence, que le barbarisme concerne un terme latin, et la barbarolexie un terme totalement étranger »). Aucun des trois grammairiens du IV siècle ne donne d'exemple.

77. Trésor royal. Voir Virgile, Énéide, op. cit., 1.119, 2.763, 5.40, etc.

78. Vêtement consistant en une sorte de pelisse. Voir Cicéron, Pro Scauro, 45 (fragment cité par Quintilien, 5.13.40). Cet exemple de barbarolexie est repris de Quintilien, 1.5.8, p. 20 : «nam mastrucam, quod est Sardum, inridens Cicero ex industria dixit »; " Quant au mot mastruca, qui est sarde, Cicéron s'en est servi à dessein et par raillerie ".

79. Mosellanus cite d'après les éditions de la Renaissance Asinius Capito (voir par exemple Auli Gellii Noctium Atticarum, Venise, Giovanni Tacuino, 1517, p. 41), là où les éditions actuelles ont Sinnius Capito. Pour la reprise que fait Mosellanus de la définition du solécisme («impar et inconveniens compositura»), voir Aulu-Gelle, Nuits attiques, op.cit., 5.20 (nous soulignons): "Soloecismus Latino vocabulo a Sinnio Capitone ejusdemque aetatis aliis imparilitas appellatus vetustioribus Latinis stribiligo dicebatur a versura videlicet et pravitate tortuosae orationis tamquam stribiligo quaedam. " « Sinnius Capiton et ses contemporains appellent imparilitas, disconvenance, le solécisme que les anciens Latins nommaient stribiligo, en raison, sans doute, de l'irrégularité et de la défectuosité qu'il introduit dans le discours, comme s'ils eussent voulu exprimer une sorte d'entortillement, stribiligo. »

À comparer avec le long développement de Quintilien (1.5.34-54); et les définitions données par Charisius, p. 266: «ut ait Cominianus. soloecismus est oratio inconsequens", "comme le dit Cominianus, le solécisme est un énoncé inconséquent »; Donat, p. 393 : «vitium [...] contra regulam artis grammaticae factum ", " un défaut [...] qui pèche contre la règle grammaticale »; Diomède, p. 453 : "contra rationem Romani sermonis disturbans orationem ", " un énoncé qui va à l'encontre des règles du latin ».

80. Les «partes orationis " («parties du discours », de l'énoncé) sont le verbe, le nom, l'adjectif, etc. Leur énumération ici est tout à fait conventionnelle d'un point de vue grammatical ; la forme ramassée et rythmée (« casus pro casu, etc. ») est propre à Diomède. En revanche, la spécification du solécisme comme l'ensemble des «accidents dans les différentes parties de l'énoncé » est seulement chez Charisius (p. 266 : «accidentia partibus orationis », « les accidents dans les parties de l'énoncé »). Donat (p.393) et Diomède (p.453) ont une autre expression, qui leur est commune: "vitium in contextu partium orationis ", " défaut contre l'arrangement des parties de l'énoncé ». Sur la notion d'accident grammatical, voir B. Colombat, Les figures de construction dans la syntaxe latine : 1500-1780, Louvain, Peeters, 1993, p. 144. 
81. Voir Donat, p. 393-394. Tout en concluant sur le seul solécisme, la dernière formule de la section que Mosellanus consacre aux défauts du discours n'en fait pas moins retour sur le trait majeur de sa méthode, humaniste s'il en est, la reprise éclairée des Anciens.

82. Dans la première édition (1516), on trouve souscrite en caractères italiques plus petits la mention suivante, qui sera supprimée dans toutes les éditions ultérieures : «Enallagen, pete ex Erasmi Copia» («Énallage: voir le De Copia d'Érasme »). Mosellanus ne décrit pas ici une figure surnuméraire. C'est une simple note à propos du paragraphe précédent, comme le signale son statut typographique. L'énallage consiste en effet à remplacer un temps, un mode, un nom, une personne, etc. par un autre temps, un autre mode, un autre nom, une autre personne, etc. Le renvoi est au De Copia verborum ac rerum d'Érasme, 1.13 (1.12 dans la princeps de 1512), chapitre « Ratio variandi per Enallagen, sive heterôsin ».

\section{AUTEURS}

\section{PETRUS MOSELLANUS}

[Peter Schade] 1494-1524 